\title{
Hepcidin expression in the liver of rats fed a magnesium-deficient diet
}

\author{
Natsumi Ishizaki, Megumi Kotani, Masayuki Funaba and Tohru Matsui* \\ Division of Applied Biosciences, Graduate School of Agriculture, Kyoto University, Kitashirakawa Oiwakecho, \\ Kyoto 606-8502, Japan \\ (Received 18 October 2010 - Revised 9 February 2011 - Accepted 27 February 2011 - First published online 18 May 2011)
}

\section{Abstract}

$\mathrm{Mg}$ deficiency accelerates Fe accumulation in the liver, which may induce various metabolic disturbances. In the present study, we examined the gene expression of Hepcidin, a peptide hormone produced in the liver to regulate intestinal Fe absorption negatively, in Mgdeficient rats. Although liver Fe concentration was significantly higher in rats fed an Mg-deficient diet for 4 weeks than in rats fed a control diet, Hepcidin expression in the liver was comparable between the dietary groups. Previous studies revealed that Fe overload up-regulated Hepcidin expression through transcriptional activation by Fe-induced bone morphogenetic protein (Bmp) 6, a growth/differentiation factor belonging to the transforming growth factor- $\beta$ family, in the liver. $\mathrm{Mg}$ deficiency up-regulated the expression of $B m p 6$ but did not affect the expression of inhibition of DNA binding 1, a sensitive Bmp-responsive gene. In addition, the expression of Bmp receptors such as activin receptor-like kinase 2 (Alk2), activin receptor type IIA (Actr $2 a)$, activin receptor type IIB (Actr2b) and Bmp type II receptor (Bmpr2) was lower in the liver of Mg-deficient rats than in that of control rats. The present study indicates that accumulation of hepatic Fe by $\mathrm{Mg}$ deficiency is a stimulant inducing Bmp6 expression but not Hepcidin expression by blunting Bmp signalling possibly resulting from down-regulation of the receptor expression. Unresponsive Hepcidin expression may have a role in Mg deficiency-induced changes related to increased liver Fe.

\section{Key words: Magnesium deficiency: Hepcidin: Liver iron content: Bone morphogenetic protein}

$\mathrm{Mg}$ is a cofactor of numerous enzymes and plays an essential role in a wide range of fundamental cellular reactions. Insufficient $\mathrm{Mg}$ intake therefore induces numerous abnormalities in rodents ${ }^{(1)}$. Mg deficiency induced oxidative stress, which was evaluated by lipid peroxidation, and apoptosis in rat liver ${ }^{(2,3)}$. In addition, TAG and total cholesterol concentrations were increased in the liver and serum of Mg-deficient rats ${ }^{(4)}$. These features resemble the altered metabolism in the liver of rats fed a high-Fe diet; Fe overload enhanced lipid peroxidation, increased apoptotic cell number and elevated liver fat concentration and serum lipid concentrations, including TAG and total cholesterol ${ }^{(5-8)}$. In view of the accumulation of hepatic Fe in Mg-deficient rats ${ }^{(2,9,10)}$, increased hepatic Fe content may cause various Mg-deficiency-related abnormalities in the liver.

Hepcidin was originally isolated from human urine as an anti-microbial peptide ${ }^{(11)}$ and is currently recognised as a hormone secreted from the liver in response to the Fe overload; it negatively regulates intestinal $\mathrm{Fe}$ absorption through internalisation and degradation of an Fe transporter, ferroportin ${ }^{(12)}$. Considering that hepatic Hepcidin transcription is triggered by excess $\mathrm{Fe}^{(13,14)}$, Mg deficiency is expected to increase Hepcidin expression in the liver; however, a previous study revealed an increase in the intestinal absorption of $\mathrm{Fe}$ in Mg-deficient rats ${ }^{(10)}$, suggesting the failure of regulatory $\mathrm{Fe}$ metabolism by Hepcidin. The present study examined the expression of hepatic Hepcidin in Mg-deficient rats.

\section{Materials and methods}

\section{Animals and diets}

A total of twelve 5-week-old male Sprague-Dawley rats were purchased from SLC Japan (Shizuoka, Japan) and cared for according to the Guide for the Care and Use of Laboratory Animals (Animal Care Committee, Kyoto University, Kyoto, Japan). They were individually housed in stainless-steel cages in a temperature-, humidity- and light-controlled room $\left(24^{\circ} \mathrm{C}, 60 \%, 12 \mathrm{~h}\right.$ light $-12 \mathrm{~h}$ dark cycle). All rats were fed a control diet (American Institute of Nutrition-93G diet) ${ }^{(15)}$ for a $5 \mathrm{~d}$ adaptation period, followed by feeding either the control diet or an Mg-deficient diet (American Institute of Nutrition93G-based diet with Mg-free mineral mixture). The Mg content

\footnotetext{
Abbreviations: Actr2, activin receptor type II; Alk, activin receptor-like kinase; Bmp, bone morphogenetic protein; Bmpr2, bone morphogenetic protein
} type II receptor; Hfe, haemochromatosis; Id1, inhibition of DNA binding 1; Tfr, transferrin receptor.

*Corresponding author: T. Matsui, fax +8175753 6344, email matsui@kais.kyoto-u.ac.jp 
determined in the control diet and the Mg-deficient diet was 49.6 and $4.2 \mathrm{mg} / 100 \mathrm{~g}$, respectively. Rats were pair-fed their respective experimental diets and were allowed free access to demineralised water for 4 weeks. After the feeding trial, the rats were killed by collecting blood from the abdominal aorta under isoflurane anaesthesia, and the liver was collected.

\section{Measurement of dietary magnesium and calcium, serum magnesium, liver iron and liver thiobarbituric acid-reactive substances}

Dietary sample, and serum and liver samples were digested with trace element-grade $\mathrm{HNO}_{3}$ and $\mathrm{H}_{2} \mathrm{O}_{2}$ (Wako, Osaka, Japan), and dietary and serum $\mathrm{Mg}$ and liver Fe were determined by atomic absorption spectrophotometry (AA-6600F; Shimadzu, Kyoto, Japan). Analytical accuracy of liver Fe was confirmed by analysis of a certified reference material of bovine liver (Standard Reference Material 1577b; National Institute of Standards and Technology, Gaithersburg, MD, USA). The liver samples were also homogenised in chilled saline by Polytron (PT1600E; Kinematica, Lucerne, Switzerland), and the homogenate was centrifuged at $105000 \boldsymbol{g}$ for $30 \mathrm{~min}$ at $4{ }^{\circ} \mathrm{C}$. The concentration of thiobarbituric acid-reactive substances in the supernatant was determined using a commercial kit (OXI-TEK TBARS Assay Kit; ZeptoMetrix, Buffalo, NY, USA) according to the manufacturer's instructions.

\section{RNA isolation and quantitative RT-PCR}

Total RNA was isolated from the liver samples using TRIzol (Invitrogen, Carlsbad, CA, USA) according to the manufacturer's instructions. Absorbance at $260 \mathrm{~nm}$ was measured to quantify RNA concentration, and simultaneously the ratio of absorbance at $260 \mathrm{~nm}$ to that at $280 \mathrm{~nm}$ was monitored to assess the purity of RNA. Quantitative RT-PCR was carried out as described previously ${ }^{(16,17)}$. The following oligonucleotides were used as PCR primers: $5^{\prime}$-gggcagaaagcaagactgat- $3^{\prime}$ and $5^{\prime}$-ttacagcatttacagcagaagagg- $3^{\prime}$ for Hepcidin (GenBank accession no. NM_053469.1); 5'-gacagcagagtcgcaatcg- $3^{\prime}$ and $5^{\prime}$-agctcacgtaaagctcatgc- $3^{\prime}$ for bone morphogenetic protein (Bmp) 6 (GenBank accession no. NM_013107); 5'-gcgagatcagtgccttgg- $3^{\prime}$ and $5^{\prime}$-tttcctcttgcctcctgaa- $3^{\prime}$ for the inhibition of DNA binding 1 (Id1) (GenBank accession no. NM_012797.2); $\quad 5^{\prime}$-actacctgcagagggactgc- $3^{\prime}$ and $5^{\prime}$-actttcaccaaagtaggcacttg- $3^{\prime}$ for haemochromatosis (Hfe, GenBank accession no. NM_053301.4); 5'-gtagcatcgggagccaac-3' and 5'-tcaaaggctgcaggaagatt-3' for Hemojuvelin (GenBank accession no. NM_001012080.1); 5'-gagttcactgacatcatcaagca- $3^{\prime}$ and $5^{\prime}$-tccagcctcacgaggagtat- $3^{\prime}$ for transferrin receptor 1 (Tfr 1 ) (GenBank accession no. NM_022712); 5'-tcagtaacatctttgcgtgcat- $3^{\prime}$ and $5^{\prime}$-gcccogataacgacatagtg- $3^{\prime}$ for Tfr2 (GenBank accession no. NM_001105916). PCR primers for activin receptor-like kinase 2 (Alk2), activin receptor-like kinase 3 (Alk3), activin receptor type IIA (Actr2a), activin receptor type IIB (Actr $2 b)$, Bmp type II receptor (Bmpr2) and glyceraldehyde-3-phosphate dehydrogenase $(G 3 p d h)$ were described previously ${ }^{(18)}$. The relative mRNA level is expressed as a ratio of the $G 3 p d h$ mRNA level.

\section{Statistical analyses}

Data are expressed as means with their standard errors. Differences between the treatments were examined by Student's $t$ test. Differences of $P<0.05$ were considered significant.

\section{Results and discussion}

Consistent with the previous results ${ }^{(2,9,10)}$, the serum concentration of $\mathrm{Mg}$ was significantly lower in rats fed the $\mathrm{Mg}$ deficient diet (Table 1). In addition, liver concentrations of $\mathrm{Fe}$ and thiobarbituric acid-reactive substances, an index of oxidative stress, were higher in the Mg-deficient group. Expression of hepatic Tfr1 was significantly lower in Mgdeficient rats than in control rats, whereas that of hepatic Tfr2 was comparable between the groups. These results were consistent with the results of Fe-overloaded mice ${ }^{(19,20)}$. Fe-responsive elements within the untranslated region are present for Tfr1 but not for Tfr 2 mRNA, which explains why the mRNA level of Tfr1 but not Tfr2 was negatively regulated by $\mathrm{Fe}$ status ${ }^{(21)}$. Thus, effects of $\mathrm{Mg}$ deficiency on the expression of Tfr 1 and Tfr2 could reflect Fe status in the liver.

$\mathrm{Mg}$ deficiency did not affect the gene transcript level of Hepcidin in the liver (Table 2). Hepcidin is a hormone that regulates intestinal $\mathrm{Fe}$ absorption negatively ${ }^{(12)}$. Hepcidin expression is transcriptionally induced in response to the elevation of hepatic $\mathrm{Fe}^{(12)}$. The present study revealed that the expression of Hepcidin in the liver is not up-regulated by $\mathrm{Mg}$ deficiency, irrespective of the enhanced accumulation of hepatic Fe. Thus, it is suggested that the lack of response of the Hepcidin expression is at least partly responsible for Mg-deficiency-induced dysregulation of Fe homeostasis.

Expression of Bmp 6 was significantly higher in Mg-deficient rats than in control rats, but $I d 1$ expression was not different between the dietary groups (Table 2). In the liver, Hepcidin is transcriptionally regulated by $\operatorname{Bmp} 6^{(22,23)}$, and $I d 1$ is a representative Bmp-responsive gene regulated at the transcription level $^{(24)}$. Previous studies revealed that Fe overload up-regulated the expression of Bmp6 and $I d 1$ in the liver ${ }^{(14,25)}$. Exogenous Bmp6 increased Hepcidin expression in Hep3B cells $^{(22)}$ as well as in the liver ${ }^{(23)}$. Furthermore, targeted disruption of the $B m p 6$ gene decreased the expression of

Table 1. Effect of magnesium deficiency on the serum concentration of magnesium, liver concentration of iron and thiobarbituric acid-reactive substances (TBARS), and hepatic expression of iron-related molecules (Mean values with their standard errors, $n 6$ )

\begin{tabular}{|c|c|c|c|c|}
\hline & \multicolumn{2}{|c|}{ Control } & \multicolumn{2}{|c|}{ Mg deficiency } \\
\hline & Mean & SEM & Mean & SEM \\
\hline Serum Mg (mg/l) & $22 \cdot 1$ & $1 \cdot 7$ & $7 \cdot 3^{\star \star}$ & $1 \cdot 2$ \\
\hline Liver Fe $(\mu \mathrm{g} / \mathrm{g})$ & $87 \cdot 8$ & $5 \cdot 8$ & $148 \cdot 1^{\star \star}$ & 14.9 \\
\hline Liver TBARS $(\mathrm{nmol} / \mathrm{g})$ & 35.9 & 2.4 & $57 \cdot 8^{\star \star}$ & $1 \cdot 7$ \\
\hline \multicolumn{5}{|l|}{ Fe-related molecules } \\
\hline Tfr1 & 1.00 & 0.18 & $0.45^{\star}$ & 0.11 \\
\hline Tfr2 & 1.00 & 0.04 & 0.93 & 0.06 \\
\hline
\end{tabular}

Tfr, transferrin receptor.

Mean values were significantly different from those of the control group: ${ }^{*} P<0.05$, ${ }^{\star \star} P<0.01$. 
Table 2. Effect of magnesium deficiency on the hepatic expression of Hepcidin, bone morphogenetic protein $(B m p) 6$, inhibition of DNA binding 1 (Id1), haemochromatosis $(\mathrm{Hfe})$, Hemojuvelin and Bmp receptors

(Mean values with their standard errors, $n 6$ )

\begin{tabular}{|c|c|c|c|c|}
\hline & \multicolumn{2}{|c|}{ Control } & \multicolumn{2}{|c|}{ Mg deficiency } \\
\hline & Mean & SEM & Mean & SEM \\
\hline Hepcidin & 1.00 & 0.13 & 0.98 & $0 \cdot 11$ \\
\hline Bmp6 & 1.00 & 0.29 & $2 \cdot 22^{\star}$ & 0.38 \\
\hline $\operatorname{ld} 1$ & 1.00 & 0.41 & 1.57 & 0.72 \\
\hline He & 1.00 & 0.05 & $0.70^{\star *}$ & 0.06 \\
\hline Hemojuvelin & 1.00 & 0.21 & $1.66^{* *}$ & 0.17 \\
\hline \multicolumn{5}{|c|}{ Bmp receptors } \\
\hline \multicolumn{5}{|c|}{ Type I receptors } \\
\hline Alk2 & 1.00 & 0.15 & $0.44^{\star *}$ & 0.06 \\
\hline Alk3 & 1.00 & $0 \cdot 10$ & 0.70 & $0 \cdot 10$ \\
\hline \multicolumn{5}{|c|}{ Type II receptors } \\
\hline Actr $2 a$ & 1.00 & 0.09 & $0.55^{\star \star}$ & 0.06 \\
\hline$A c t r 2 b$ & 1.00 & 0.08 & $0.65^{\star}$ & 0.09 \\
\hline Bmpr2 & 1.00 & 0.13 & $0.51^{*}$ & 0.04 \\
\hline
\end{tabular}

Alk, activin receptor-like kinase; Actr2, activin receptor type II; Bmpr2, Bmp type II receptor.

Mean values were significantly different from those of the control group: ${ }^{\star} P<0.05,{ }^{\star \star} P<0.01$.

Hepcidin and accumulated Fe in the liver ${ }^{(23,26)}$. Thus, Bmp6 is a signal mediator linking $\mathrm{Fe}$ accumulation and Hepcidin expression, although transcriptional activation of the $B m p 6$ gene by excess Fe accumulation is currently unclear at the molecular level ${ }^{(27)}$. In the present study, the expression of Вmp6 was increased $2 \cdot 2$-fold in rats fed the Mg-deficient diet. The extent of the response was comparable with a previous result; feeding a high-Fe diet for 7 weeks resulted in a 1.8-fold increase in $B m p 6$ expression and sevenfold increase in Hepcidin expression in DBA/2 mice ${ }^{(14)}$. Mg deficiency may blunt the Bmp pathway by altering the function of factors involved in hepatic Hepcidin induction.

The gene transcript level of Hfe was significantly lower in Mg-deficient rats than in control rats, whereas that of Hemojuvelin was higher in Mg-deficient rats (Table 2). Upon Bmp binding to the two types of receptors, i.e. type I and type II serine/threonine receptors, the receptor complex phosphorylates and activates Smad1/5/8, leading to transcriptional activation of the target genes such as $I d 1^{(28)}$. The strength and duration of the Bmp signal are regulated at multiple steps; expression of co-receptors for Bmp is involved in the finetuning of Bmp signalling ${ }^{(28)}$. Previous studies revealed that Hemojuvelin, which is a gene product of Hfe 2 and a coreceptor of Bmp, including Bmp6, enhances Hepcidin expression both in vitro and in vivo ${ }^{(22,29,30)}$. In view of the up-regulation of Hemojuvelin expression in Mg-deficient rats, the co-receptor is unlikely to be involved in the unresponsiveness to Bmp6.

Recently, Kautz et al. ${ }^{(25)}$ revealed that the expression of Bmp6 was enhanced in Hfe-null mice, but hepatic Bmp signalling, such as phosphorylation of Smad1/5/8 and Id1 expression, was not accelerated. Similar results were also recently obtained in patients with hereditary haemochromatosis with mutation of the HFE gene ${ }^{(31)}$. In the liver of
Fe-overloaded mice, both Hfe and Hemojuvelin expressions were increased $^{(20)}$. Therefore, the blunting of Bmp signalling at the gene transcript level of Hepcidin may be explained by the result that $\mathrm{Mg}$ deficiency down-regulated Hfe expression in the liver, although up-regulation of Hepcidin expression in response to Bmp2, Bmp4 and Bmp9 in primary hepatocytes from wild-type mice was comparable with those from Hfe-null mice ${ }^{(32)}$.

Down-regulation of the expression of Bmp receptors is possibly related to blunting of Bmp signalling in Mg-deficient rats. Among Bmp receptors, expression of hepatic Alk2, Actr $2 a$, Actr $2 b$ and Bmpr2 was significantly lower in Mg-deficient rats than in control rats (Table 2); expression of activin receptor-like kinase 6 (Alk $\sigma$ ), a Bmp type I receptor, was not significant (data not shown). Receptor expression level also determines the strength of Bmp signalling ${ }^{(28,33)}$.

In conclusion, the accumulation of hepatic $\mathrm{Fe}$ by $\mathrm{Mg}$ deficiency is a stimulant inducing $B m p 6$ expression but not Hepcidin expression by blunting Bmp signalling possibly resulting from down-regulation of the receptor expression. Unresponsive Hepcidin expression may have a role in Mg-deficiency-induced changes related to increased liver Fe.

\section{Acknowledgements}

The present study received no specific grant from any funding agency in the public, commercial or not-for profit sectors. N. I. and T. M. designed the study; N. I. and M. K. performed the study; N. I., M. F. and T. M. analysed the data and wrote the manuscript. All authors discussed the results and approved the manuscript in its final version. The authors declare no conflict of interest.

\section{References}

1. Mazur A, Maier JA, Rock E, et al. (2007) Magnesium and the inflammatory response: potential physiopathological implications. Arch Biochem Biophys 458, 48-56.

2. Vormann J, Günther T, Höllriegl V, et al. (1995) Effect of various degree and duration of magnesium deficiency on lipid peroxidation and mineral metabolism in rats. Nutr Biochem 6, 681-688.

3. Martin H, Uring-Lambert B, Adrian M, et al. (2008) Effects of long-term dietary intake of magnesium on oxidative stress, apoptosis and ageing in rat liver. Magnes Res 21, 124-130.

4. Akiyama S, Uehara M, Katsumata S, et al. (2008) Effects of dietary ascorbic acid supplementation on lipid peroxidation and the lipid content in the liver and serum of magnesiumdeficient rats. Magnes Res 21, 232-236.

5. Wang GS, Eriksson LC, Xia L, et al. (1999) Dietary iron overload inhibits carbon tetrachloride-induced promotion in chemical hepatocarcinogenesis: effects on cell proliferation, apoptosis, and antioxidation. J Hepatol 30, 689-698.

6. Fischer JG, Glauert HP, Yin T, et al. (2002) Moderate iron overload enhances lipid peroxidation in livers of rats, but does not affect NF- $\mathrm{KB}$ activation induced by the peroxisome proliferator, Wy-14,643. J Nutr 132, 2525-2531.

7. Turbino-Ribeiro SM, Silva ME, Chianca DA Jr, et al. (2003) Iron overload in hypercholesterolemic rats affects iron homeostasis and serum lipids but not blood pressure. J Nutr 133, 15-20. 
8. Silva M, Silva ME, de Paula $\mathrm{H}$, et al. (2008) Iron overload alters glucose homeostasis, causes liver steatosis, and increases serum triacylglycerols in rats. Nutr Res $\mathbf{2 8}$ 391-398.

9. Kimura M \& Yokoi K (1996) Iron accumulation in tissues of magnesium-deficient rats with dietary iron overload. Biol Trace Elem Res 51, 177-197.

10. Sanchez-Morito N, Planells E, Aranda P, et al. (2000) Influence of magnesium deficiency on the bioavailability and tissue distribution of iron in the rat. J Nutr Biochem 11, 103-108.

11. Park CH, Valore EV, Waring AJ, et al. (2001) Hepcidin, a urinary antimicrobial peptide synthesized in the liver. $J$ Biol Chem 276, 7806-7810.

12. Lee PL \& Beutler E (2009) Regulation of hepcidin and ironoverload disease. Annu Rev Pathol 4, 489-515.

13. Pigeon C, Ilyin G, Courselaud B, et al. (2001) A new mouse liver-specific gene, encoding a protein homologous to human antimicrobial peptide hepcidin, is overexpressed during iron overload. J Biol Chem 276, 7811-7819.

14. Kautz L, Meynard D, Monnier A, et al. (2008) Iron regulates phosphorylation of $S$ mad1/5/8 and gene expression of Bmp6, Smad7, Id1, and Atoh8 in the mouse liver. Blood 112, 1503-1509.

15. Reeves PG (1997) Components of the AIN-93 diets as improvements in the AIN-76A diet. J Nutr 127, 838S-841S.

16. Furutani Y, Murakami M \& Funaba M (2009) Differential responses to oxidative stress and calcium influx on expression of the transforming growth factor- $\beta$ family in myoblasts and myotubes. Cell Biochem Funct 27, 578-582.

17. Suenaga M, Matsui T \& Funaba M (2010) BMP inhibition with dorsomorphin limits adipogenic potential of preadipocytes. $J$ Vet Med Sci 72, 373-377.

18. Nishino Y, Ooishi R, Kurokawa S, et al. (2009) Gene expression of the TGF- $\beta$ family in rat brain infected with Borna disease virus. Microbes Infect 11, 737-743.

19. Fleming RE, Migas MC, Holden CC, et al. (2000) Transferrin receptor 2: continued expression in mouse liver in the face of iron overload and in hereditary hemochromatosis. Proc Natl Acad Sci U S A 97, 2214-2219.

20. Theurl I, Ludwiczek S, Eller P, et al. (2005) Pathways for the regulation of body iron homeostasis in response to experimental iron overload. J Hepatol 43, 711-719.
21. Trinder D \& Baker E (2003) Transferrin receptor 2: a new molecule in iron metabolism. Int J Biochem Cell Biol 35 , 292-296.

22. Babitt JL, Huang FW, Xia Y, et al. (2007) Modulation of bone morphogenetic protein signaling in vivo regulates systemic iron balance. J Clin Invest 117, 1933-1939.

23. Andriopoulos B Jr, Corradini E, Xia Y, et al. (2009) BMP6 is a key endogenous regulator of hepcidin expression and iron metabolism. Nat Genet 41, 482-487.

24. Korchynskyi O \& ten Dijke P (2002) Identification and functional characterization of distinct critically important bone morphogenetic protein-specific response elements in the Id1 promoter. J Biol Chem 277, 4883-4891.

25. Kautz L, Meynard D, Besson-Fournier C, et al. (2009) BMP/ Smad signaling is not enhanced in Hfe-deficient mice despite increased Bmp6 expression. Blood 114, 2515-2520.

26. Meynard D, Kautz L, Darnaud V, et al. (2009) Lack of the bone morphogenetic protein BMP6 induces massive iron overload. Nat Genet 41, 478-481.

27. Camaschella C (2009) BMP6 orchestrates iron metabolism. Nat Genet 41, 386-388.

28. Miyazono K, Kamiya Y \& Morikawa M (2010) Bone morphogenetic protein receptors and signal transduction. J Biochem 147, 35-51.

29. Babitt JL, Huang FW, Wrighting DM, et al. (2006) Bone morphogenetic protein signaling by hemojuvelin regulates hepcidin expression. Nat Genet 38, 531-539.

30. Xia Y, Babitt JL, Sidis Y, et al. (2008) Hemojuvelin regulates hepcidin expression via a selective subset of BMP ligands and receptors independently of neogenin. Blood 111, $5195-5204$

31. Ryan JD, Ryan E, Fabre A, et al. (2010) Defective bone morphogenic protein signaling underlies hepcidin deficiency in HFE hereditary hemochromatosis. Hepatology 52, $1266-1273$.

32. Truksa J, Peng H, Lee P, et al. (2006) Bone morphogenetic proteins 2, 4, and 9 stimulate murine hepcidin 1 expression independently of Hfe, transferrin receptor 2 (Tfr2), and IL-6. Proc Natl Acad Sci U S A 103, 10289-10293.

33. Murakami M, Kawachi H, Ogawa K, et al. (2009) Receptor expression modulates the specificity of transforming growth factor- $\beta$ signaling pathways. Genes Cells 14, 469-482. 